\title{
Lévinas, Michaël
}

\section{Geb. 18. 4. 1949 in Paris}

Nach dem Abschluß seines Kompositionsstudiums in der Klasse Messiaens gründete L. 1973 zusammen mit Grisey, Murail und Roger Tessier die Pariser Gruppe "Itinéraire", ein auf die feste Zusammenarbeit zwischen Komponisten und Instrumentalisten gestütztes Ensemble, in dessen Umfeld sich die Poetik der sogenannten "musique spectrale« entwickelte. Im Mittelpunkt der Forschung dieser musikalischen Richtung stehen die interne Struktur des Klanges und die Möglichkeiten seiner Entfaltung; sie können dank der wissenschaftlichen Analyse des natürlichen Spektrums minutiös in dessen Ein- und Ausschwingvorgang sowie in dessen dynamische Verwandlung bestimmt werden.

L.s Adaption dieser Poetik war schon in seinem frühesten Schaffen unabhängig und originell. Ausgehend von dem Konzept eines immer neu zu erfindenden musikalischen Materials, das stark von dem Stockhausens geprägt wurde - L. nahm 1972 an den Darmstädter Ferienkursen teil, als Stockhausen seine Stimmung gründlich analysierte -, erforschte der Komponist unter Verwendung elektroakustischer und elektronischer Mittel diejenigen Aspekte des Klanges und dessen instrumentaler Hervorbringung, die normalerweise in der Musik als nebensächlich wenn nicht als Störungselemente betrachtet werden. Diese treten in seinen Werken in der Vordergrund: Appels ("Rufe«; 1974) ist eine Studie über die Schwingungen, welche die Klänge eines Bläserseptettes über den Resonanzkörpern von Klavier, Kontrabaß bzw. Schlagzeuginstrumenten erzeugen. L. experimentiert mit der Verwandlung der Klänge im Raum und der Möglichkeit, einen hybriden Klang zu schaffen, der immer von einem 'Doppelgänger begleitet wird. So werden auch die Phänomene des Widerhalls zentrale Forschungsgebiete seiner $\mathrm{Mu}$ sik, z. B. in Ouverture pur une fête étrange für Doppelorchester ("Ouvertüre für ein seltsames Fest «; 1979) und in Contrepoints Irréels - Rencontres für vier Flöten und Tonband (»Irreale Kontrapunkte - Begegnungen «; 1980); ebenso das Phänomen des elektronisch erzeugten Aufschubs (»delay"), u. a. in Voix des voix für neun Instrumente und Tonband ("Stimme der Stimmen «; 1984).

In einem 1982 in Darmstadt gehaltenen Vor- trag Qu'est-ce que l'instrumental? unterschied L. den sinstrumentalen Klang vom sreinen Klang aufgrund seiner Eigenschaft, die gestischen Spuren seiner Hervorbringung zu bewahren. Schon in Arsis et Thesis für verstärkte Baßflöte (1971) sind die Atemzüge des Aufführenden und sogar die Ein- und Ausschwingvorgänge sehr genau vorbestimmt und ausgeschrieben: Die Hervorbringung und die damit verbundene Gestik werden als strukturelles Element hervorgehoben. Hier offenbart sich bereits ein weiterer Kernpunkt von L.s Ästhetik, nämlich seine Vorliebe für den theatralischen Aspekt. Sie kulminiert im »spectacle musical« La conférence des oiseaux ("Die Konferenz der Vögel«, Jean-Claude Carrière nach Fahrid Uddin Attar; 1985) und in der Oper GO-gol (M.L. nach zwei Novellen von Nikolaj Gogol'; Straßburg 1996). Aber auch in seinen instrumentalen Werken kann man beobachten, wie der Klang selbst zur Schau gestellt und dank der Zusammenarbeit von Instrument und menschlichem Körper inszeniert wird. Dieser Aspekt wird durch die ausgiebige Verwendung spräparierter` Instrumente und klare Verweise auf Außermusikalisches verstärkt: In dem von Samuel Becketts "Endspiel « inspirierten Stück Clov et Hamm (1973) ähnelt die Posaune durch den vorgeschriebenen Dämpfer der tiefen Stimme eines betrunkenen "clochard ", während in Le Rire $d u$ Gilles ("Das Lachen des Gilles" [des Einfaltspinsels, Person des komisches Theaters]; 1981, zweite Version 1982) das menschliche Lachen durch spezielle Ausführungstechniken der Bläserinstrumente imitiert wird, so daß das Saxophon einen hybriden Klang, "halb Trompete - halb Clown - halb Saxophon-Stimme« erzeugt.

Noten: Salabert (Paris).

Dokumente: Qu'est-ce que l'instrumental? in Algorithmus, Klang, Natur. Abkehr vom Materialdenken?, hrsg. von Fr. Hommel, Mainz, 1984, 35-40 (Darmstädter Beiträge zur Neuen Musik 19). Le compositeur trouvère. Ecrits et entretiens, 1982-2002, hrsg. von P. A. Castanet und D. Cohen-Lévinas, Paris 2002.

Literatur: CAstanet, P.A.: La musique et son double. L'esthétique de M.L. in La revue musicale 421-424 (1991), 73-91. Cazaban, C.: M. L. ou la quête du concert imaginaire, ebd. 169-189.

Pietro Cavallotti 